\title{
The role of dust, grit and phytoliths in tooth wear
}

\author{
Peter W. Lucas ${ }^{1, *}$, Adam van Casteren ${ }^{1}$, Khaled Al-Fadhalah², \\ Abdulwahab S. Almusallam ${ }^{3}$, Amanda G. Henry ${ }^{4}$, Shaji Michael ${ }^{5}$, \\ Jörg Watzke ${ }^{4}$, David A. Reed ${ }^{6}$, Thomas G. H. Diekwisch ${ }^{6}$, David S. Strait ${ }^{7}$ \& \\ Anthony G. Atkins ${ }^{8}$
}

1) Department of Bioclinical Sciences, Faculty of Dentistry, P.O. Box 24923, Safat 13110, Kuwait University, Kuwait ('corresponding author's e-mail: peterwlucas@gmail.com)

2) Department of Mechanical Engineering, College of Engineering and Petroleum, Kuwait University, P.O. Box 5969, Safat 13060, Kuwait

3) Department of Chemical Engineering, College of Engineering and Petroleum, Kuwait University, P.O. Box 5969, Safat 13060, Kuwait

4) Plant Foods in Hominin Dietary Ecology Group, Max Planck Institute for Evolutionary Anthropology, Deutscher Platz 6, D-04103 Leipzig, Germany

5) Nanotechnology Research Facility, College of Engineering and Petroleum, Kuwait University, P.O. Box 5969, Safat 13060, Kuwait

6) Department of Oral Biology, Brodie Laboratory for Craniofacial Genetics, 801 South Paulina Street, Chicago, IL60612, USA

7) Department of Anthropology, University at Albany, Albany, NY 12222, USA

8) School of Construction Management and Engineering, University of Reading, Whiteknights, P.O. Box 219, Reading RG6 6AW, UK

Received 25 June 2013, final version received 9 Oct. 2013, accepted 10 Oct. 2013

Lucas, P. W., van Casteren, A., Al-Fadhalah, K., Almusallam, A. S., Henry, A. G., Michael, S., Watzke, J., Reed, D. A., Diekwisch, T. G. H., Strait, D. S. \& Atkins, A. G. 2014: The role of dust, grit and phytoliths in tooth wear. - Ann. Zool. Fennici 51: 143-152.

The threat of wear to dental enamel from hard particles of silica or silicates may have exerted great selective pressure on mammals. Increasing the hardness of enamel helps to forestall this, but capacity for variation is small because the tissue is almost entirely composed of hydroxyapatite. Hard though it is, enamel also displays considerable toughness, which is important in setting the sharpness of particles (defined as an attack angle) necessary to wear it. Added to the threat from environmental silica(tes) are phytoliths, particles of opaline silica embedded in plant tissues. We show here that phytoliths have very different properties to grit and dust and are unlikely to wear enamel. However, phytoliths would tend to fracture between teeth under similar conditions, so resembling natural agents of wear. In this context, we suggest that phytoliths could represent an example of mimicry, forming an example of a feeding deterrent operating by deceit.

Throughout his career, Mikael Fortelius has produced many novel insights into aspects of the evolution and adaptation of the mammalian dentition. Outstanding examples of his contribu- tions are those that deal with tooth wear. This interest dates back to his thesis days (Fortelius 1985) and continues through his seminal papers with Christine Janis (Janis \& Fortelius 1988) 
and Nikos Solounias (Fortelius \& Solounias 2000), right up to his most recent collaborations (Kaiser et al. 2013). Offered in honour of Mikael's career, our current paper builds on an effort to model dental wear processes at the nanoscale (Lucas et al. 2013), attempting in some small way to emulate Mikael's ingenuity in offering new dimensions to the subject.

\section{Introduction}

Tooth wear in mammals jeopardizes efficient food breakdown in the mouth by gradually erasing key features of the working surfaces of tooth crowns (Lucas 2004). Research suggests that this effacement of the working surfaces eventually impinges on the nutritive status of an animal (Lanyon \& Sanson 1986), jeopardizing reproductive viability if wear advances too rapidly (King et al. 2005, Cuozzo \& Sauther 2006). Mammals, generally possessing teeth of limited growth, commonly adopt one of two common anatomical strategies to delay functional tooth loss. Many herbivorous mammals, chewing thin sheets of material that do not propagate cracks, have increased their tooth crown heights (hypsodonty). Vertical symmetry preserves features critical to breaking down these foods, such as the length of enamel ridges exposed on the working surface, throughout most of a tooth's lifespan (Fortelius 1985). Other mammals such as humans, pigs and bears, which eat bulk foods that are much harder but crack easily, have bluntcusped molars with thickened enamel (bunodonty). However, both hypsodont and bunodont teeth can eventually be worn down to the gum line and fail to function completely.

Several studies now show how tooth wear seems to decrease the overall fitness of mammals (King et al. 2005, Cuozzo \& Sauther 2006). However, there is still much presumption in advocating wear as the main evolutionary driver of either hyspodonty or bunodonty. While wear is the gradual loss of tissue volume resulting from successive microfractures, catastrophic fracture of teeth can end the utility of teeth immediately by chipping off a large slab of enamel or even by splitting a tooth crown right down its middle (Chai et al. 2011). Theory and experiments show that thickening the enamel, or making the whole tooth crown stouter or taller, all strengthen the crown against the threat of catastrophic fracture (Barani et al. 2012, Lawn et al. 2013). There is good evidence for chipping and fracture in bunodont dentitions (Constantino et al. 2010, Lee et al. 2011), but not for hypsodont ones. This could reflect intense pressure to avoid this in the latter, but much evidence suggests that hypsodonty evolved to combat wear (Strömberg et al. 2013). While contacts with large hard objects lead to large-scale fractures, it is contacts with small ones that lead to wear (Lucas et al. 2008, Lucas et al. 2013). The threshold particle size distinguishing between contacts that could lead to wholesale fractures of the enamel cap (from inside-to-out) or to chipping versus those that could cause surface wear, is low-millimetre (Lucas et al. 2008). We thus focus on smaller particles as wear candidates here and ask several questions.

\section{What wears teeth?}

The traditional culprits are siliceous grit and dust, where the latter is an airborne subset of particles $<100 \mu \mathrm{m}$ diameter. However, while the presence of tiny marks on the working surfaces of crowns indicates contact with these particles during chewing, it does not prove that teeth have lost tissue volume (which is the definition of wear). Instead, such marks may merely represent rearrangement of the tooth surface via plastic deformation. Eventually, a rubbing process like this will lead to wear, but not nearly as quickly as if contacts fractured away small amounts of tissue from tooth surfaces via abrasion. The latter is only feasible against particles that are sufficiently hard and also that have a sufficient sharpness, defined as an angle of attack (Atkins \& Liu 2007, Lucas et al. 2013). This angle is that between the particle and the tooth surface measured in the direction of motion (Fig. 1). Its critical value is set by the toughness of the tissue being abraded (Atkins \& Liu 2007, Atkins 2009a, 2009b) and much larger for dentine than for enamel because dentine is tougher (Lucas et al. 2013). Thus, enamel can be damaged by blunter particles than those that wear dentine. Compared with dentine, enamel is relatively 
brittle (Bajaj \& Arola 2009) and has been shown to fracture at surprisingly small (sub-prismatic) scales (Guidoni et al. 2009, Lucas et al. 2013). We have indicated that particles much harder than enamel (Lucas et al. 2013), such as the many types of silica and silicate that make up about $90 \%$ of the earth's crust (Lutgens \& Tarbuck 2000), are most likely to abrade it. However, complicating the picture is that plants produce a type of non-crystalline silica, usually as small separate particles, called phytoliths, which are thought to provide a form of mechanical defence (Piperno 2006). Silica levels in faeces correlate with the degree of hypsodonty in herbivores (Hummel et al. 2011), with the quantity of silica from soil outstripping that from phytoliths, at least in grazers (Damuth \& Janis 2011). Quartz in soil can definitely abrade tooth enamel (remove tissue), while phytoliths from plants appear not to be able to do so (Lucas et al.2013).

\section{How can wear be prevented?}

There appears to be two possibilities: (1) anatomical adaptations in mineralized tissue properties that might downgrade abrasive contacts to pure rubbing, and (2) physiological mechanisms for detecting such particles so as to avoid them. With respect to dental anatomy, mammalian enamel is an exceptionally hard mineralized tissue, particularly in its surface layer where it may reach $6 \mathrm{GPa}$ (Cuy et al. 2002). These levels of mineralization, which can be maintained to a degree by ionic interactions with the mouth, are important in limiting damage. However, physiological mechanisms to detect potential deleterious contacts must otherwise be of paramount importance for an individual animal. If sensory perceptions can be formed that relate to the sensation of 'grittiness' (Imai et al. 1995, Kadohisa et al. 2005), then this may signal to the animal that it should feed on other plant sources.

Most airborne particles, unless resulting from recent explosive fractures, are 'weathered' with few or no sharp edges, and thus lack the attack angles needed to damage enamel. However, if particles fracture in the mouth during chewing, this will immediately generate new surfaces with potentially dangerous attack angles. To this end

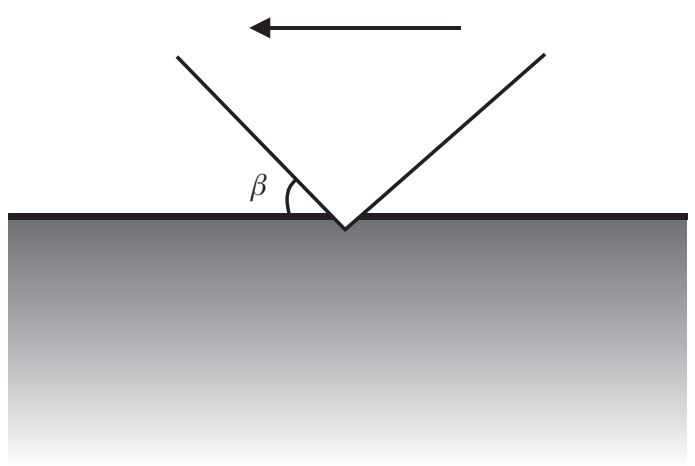

Fig. 1. Schematic diagram to show sliding contact between a flat surface and a particle hard enough to make a rigid plastic contact with it. The attack angle $\beta$ is that between the leading edge of the particle in the direction of motion (arrowed) and the surface. The toughness of the surface $\left(K_{\mathrm{c}}^{2} / E_{\mathrm{r}}\right.$ in the terminology of this paper) determines the threshold attack angle above which abrasion is possible. At lower angles, the particle has a rubbing action that distorts the surface without removing any tissue from it (Atkins \& Liu 2007).

here, we investigate the forces required to fracture siliceous grit and dust, which would turn a rubbing agent into an abrasive one.

\section{How can plants prevent being eaten?}

We can also ask what strategies plants adopt in order to deter mammals from feeding on them. What is the role of opaline silica produced by plants? Mammals need to avoid tooth wear and do all they can to stop it. Experiments show that feeding on grasses by sheep induces phytolith formation, which then deters their further consumption (Massey et al. 2007, Massey et al. 2009). To have this effect, sheep must be able to perceive the presence of phytoliths within the mouth prior to ingestion. However, if phytoliths do not wear mammalian enamel, why are herbivores deterred from feeding? Here we speculate on the possibility that plants are deceiving vertebrates by formulating phytoliths as grit/dust mimics.

\section{Material and methods}

Phytoliths were obtained from the leaves of two 

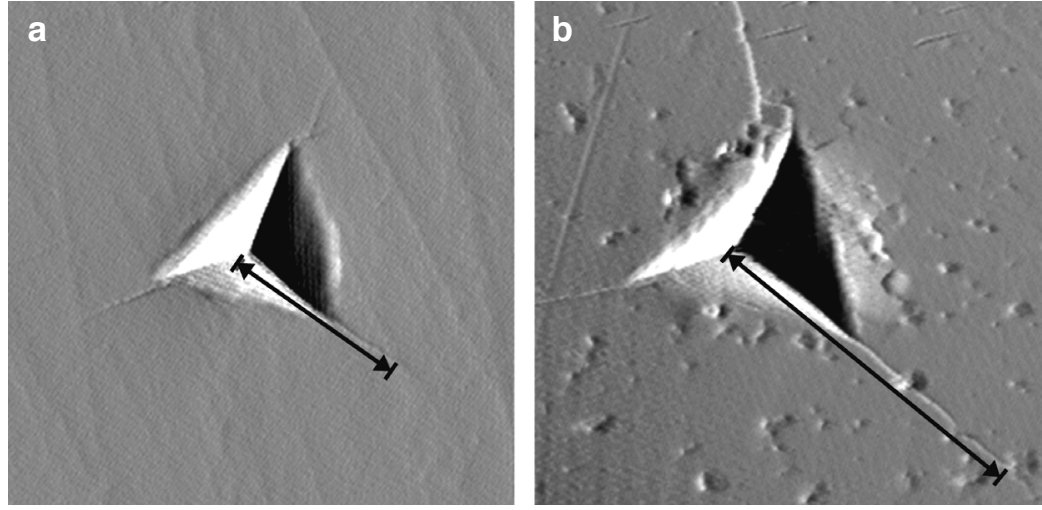

Fig. 2. Cube corner indentations in (a) silica grit and (b) phytoliths from grass (Ampelodesmos mauritanicus) leaves produced cracks of $1 \mu \mathrm{m}$ in length in the grit particle and $2.5 \mu \mathrm{m}$ in the phytolith. The fracture toughness of these particles was computed from these crack lengths.

grasses: Dactylis glomerata and Ampelodesmos mauritanicus. Low-temperature acid extraction (Jones \& Milne 1966) was employed to obtain them since this appears to leave phytolith physical properties intact. Dust and grit were obtained from Kuwaiti landscapes. Samples of these particles were embedded in resin and subjected to nanoindentation (Hysitron Ubi 1, Eden Prairie $\mathrm{MN}$ ) with a cube corner diamond tip operating at a force of $8 \mathrm{mN}$. This tip was used to obtain the reduced elastic modulus $E_{\mathrm{r}}$ and indentation hardness $H$ following standard analysis (Oliver \& Pharr 1992). Indentations made with it also produced cracks (Fig. 2), from which the fracture toughness $K_{\mathrm{c}}$ could be estimated from

$$
K_{\mathrm{c}}=\alpha\left(E_{\mathrm{r}} / H\right)^{0.5}\left(P / c^{1.5}\right)
$$

where the force $P$ was $0.008 \mathrm{~N}$ and $c$ was the maximum crack length measured from the centre of indentation. The coefficient $\alpha$ was taken as 0.04 (Pharr 1998). Built on an initial idea by Anstis et al. (1981), this toughness method has been proven to be scale-independent (Pharr 1998). Cracks of $2-3 \mu \mathrm{m}$ in length could be produced reliably with this technique (Fig. 2).

Grit and dust particles, roughly spherical with a size range of $0.09-2.5 \mathrm{~mm}$, were then measured individually with a micrometer (equipped with tungsten carbide hardened faces) to obtain their effective diameter $d$ (Horex IP 54 , Germany). These particles were placed on an aluminium plate, which was softer than the particles and thus tended to deform around them. Tests were then performed by compressing them with a tungsten carbide plate attached to a hand- cranked portable testing machine. Force was recorded with a load cell and displacement via a linear variable differential transformer (LVDT). From these outputs, a force-displacement graph was generated, allowing initial and peak forces to be easily observed. We then estimated the failure strength $\sigma_{\mathrm{F}}$ of the particles as though they were spherical from

$$
\sigma_{\mathrm{F}}=P_{\mathrm{F}} / d^{2}
$$

where $P_{\mathrm{F}}$ was the peak force (McDowell \& Bolton 1998). This result, due to Hiramatsu \& Oka (1966), is an attempt to obtain a central tensile stress at failure. The calculation is inaccurate if particles fracture at their surfaces (Shipway \& Hutchings 1993a, 1993b, 1996), but using a soft (aluminium) plate that can deform around the particle, as here, may help to reduce surface failures (McDowell \& Bolton 1998). As in McDowell and Bolton's study, multiple force spikes were usually obtained in the current tests. We chose the peak force here to calculate the fracture stress from Eq. 2. For ease of analysis and to help limit the effect of probable heterogeneous composition of the dust and grit, we classified particle sizes into four size categories, $\leq 0.1 \mathrm{~mm}, 0.1-0.5 \mathrm{~mm}, 0.5-1.0 \mathrm{~mm}$ and 1.0-2.5 mm (McDowell \& Bolton 1998). Average diameters and peak forces were calculated for each of the above categories, plotting the data using logarithmic axes (Fig. 3). All the data were analysed using the $\mathrm{R}$ statistical package (R Core Team 2013). Due to their small size $(<40 \mu \mathrm{m}$ in our sample), it was not possible to perform these compression tests on phytoliths. 


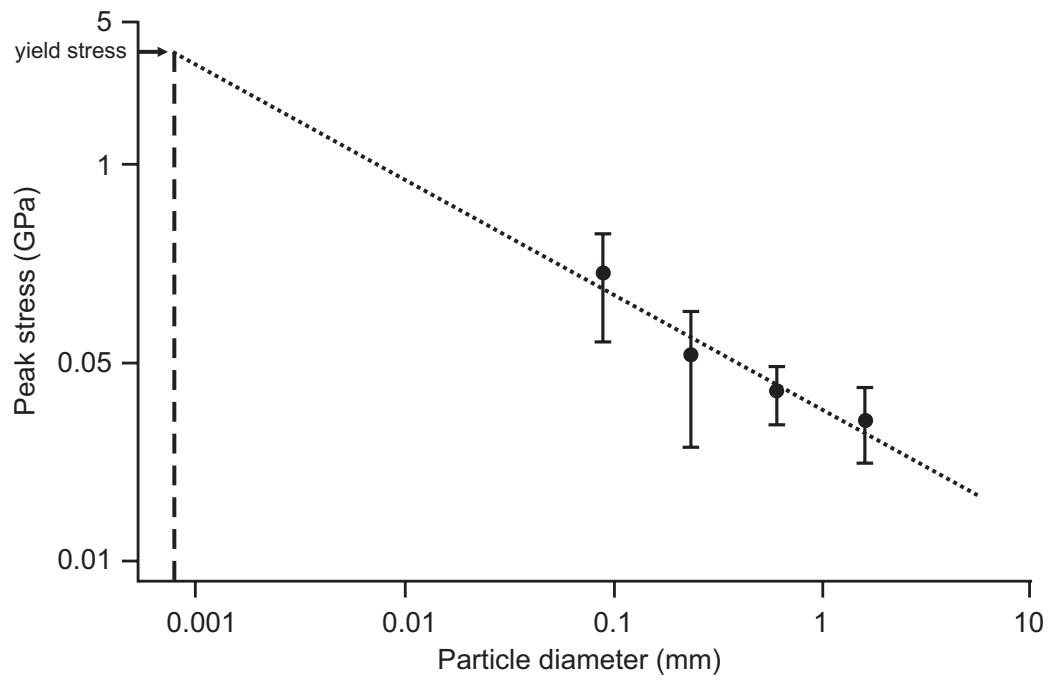

Fig. 3. Relationship between peak fracture stress of grit/dust particles in compression plotted against particle diameter. Results are from 22 tests, grouped into four size classes (error bars indicate 1 SD). The fracture stress rises in smaller particles as predicted by fracture mechanics (see Discussion). Extrapolating the regression line to the yield stress (arrowed), which is one-third of the hardness value (Table 1), suggests this stress is reached in particles of $\sim 0.5 \mu \mathrm{m}$ in diameter, meaning that smaller particles would no longer crack in compression.

\section{Results}

Presented are the measured properties of the three types of particle (Table 1). Much larger indentations and cracks were recorded for phytoliths as compared with those for silica grit at the same force (Fig. 2) with correspondingly lower property values. The fracture stress for dust and grit particles increased as particle size decreased. The regression line (Fig. 3) fitting to the data was $\sigma_{\mathrm{F}}=59.7 d^{-0.57}\left(r^{2}=0.887\right)$. The actual forces involved ranged from $0.9 \mathrm{~N}$ for the smallest particles to over $150 \mathrm{~N}$ for those in the millimetre range.

\section{Discussion}

Our property data values for dust and grit correspond with those in the limited literature on the subject for a variety of silica and silicates (Broz et al. 2006, Whitney et al. 2007, Riede \& Wheeler 2009, Daphalapurkar et al. 2011). The data scatter, found even in a supposedly homogeneous sand sample (Daphalapurkar et al. 2011), probably reflects impurities of composition as much as it does the difficulties of impaling very small particles. The elemental composition of dust/grit particles apparently made of quartz is complex (Lucas et al. 2013) and may reflect a

Table 1. Phytolith properties compared with those of quartz grit. Data are means \pm SD.

\begin{tabular}{lccc}
\hline Material & $\begin{array}{c}\text { Reduced elastic modulus, } \\
E_{r}(\mathrm{GPa})\end{array}$ & $\begin{array}{c}\text { Indentation hardness, } \\
H(\mathrm{MPa})\end{array}$ & $\begin{array}{c}\text { Fracture toughness, } \\
K_{\mathrm{c}}\left(\mathrm{MPa} \mathrm{m}^{1 / 2}\right)\end{array}$ \\
\hline Quartz $(n=13)$ & $94.16 \pm 2.29$ & $13.53 \pm 0.19$ & $0.68 \pm 0.08$ \\
Ampelodesmos mauritanicus $(n=12)$ & $21.6 \pm 2.51$ & $3.03 \pm 0.10$ & $0.22 \pm 0.05$ \\
Dactylis glomerata $(n=17)$ & $20.2 \pm 1.19$ & $2.76 \pm 0.11$ & $0.28 \pm 0.04$ \\
Enamel $^{*}$ & $60-100$ & $3-6$ & $0.7-2.2$ \\
Dentine $^{*}$ & 22 & 0.6 & 2.0 \\
\hline
\end{tabular}

*from Lucas (2004). 
coating of very fine silicates (Engelbrecht et al. 2008). Despite this, the data (Table 1) are tightly distributed around the mean.

Fracture mechanics predicts that the fracture stress of an object of given shape reduces as the square root of its typical dimension (Atkins \& Mai 1985). Theory and experiment in compression tests fully bear this out (Kendall 1978a, 1978b, Darvell 1990). This is the reason why our data are plotted with logarithmic axes (Fig. 3). Our results are consonant with the idea that $\sigma_{\mathrm{F}}$ is proportional to $d^{-0.5}$ (Fig. 3) although particle shape irregularities are probably important in interfering with this prediction and producing scatter. At small enough particle sizes, the fracture stress exceeds the yield stress, so such particles will flow rather than fracture (Kendall 1978a). In compression, this forms a comminution limit (Kendall 1978b). Such a brittle-ductile deformation transition is pervasive in materials (Atkins \& Mai 1985). Although we did not observe it directly here due to the impracticalities of performing compression tests on such small particles, we predict from our regression line (Fig. 3) that particles below $0.5 \mu \mathrm{m}$ in diameter will not crack and thus no longer pose an abrasive threat. There is another way to calculate the threshold size $d_{\text {crit }}$ from the formula derived from fundamentals of fracture for the compression of particles by Kendall (1978a, 1978b), which is

$$
d_{\text {crit }}=(32 / 3)\left(K_{\mathrm{c}}^{2} / \sigma_{y}^{2}\right)
$$

A very similar estimate has been proposed by Puttick et al. (1979) to apply to indentations. Taking $H \approx 3 \sigma_{y}$ (Atkins \& Mai 1985) and inserting data from Table 1 into this equation gives estimates of $d_{\text {crit }}=0.24 \mu \mathrm{m}$ (grit), $d_{\text {crit }}=0.51 \mu \mathrm{m}$ (A. mauritanicus phytoliths) and $d_{\text {crit }}=0.99 \mu \mathrm{m}$ (D. glomerata phytoliths).

With these results in hand, we now address the questions posed in the Introduction.

\section{What wears teeth and how might wear be prevented?}

Physiological mechanisms to detect small particles in the mouth are certainly present. The lower end of the particle size range of dust particles seems to correspond to the low-micron particle size detection limit reported for humans in the mouth. However, this limit has been found to vary considerably between studies (Engelen $e t$ al. 2005) and it may well simply be that it is not a size limit at all. To our knowledge, receptors in and around the mouth that could respond to very tiny displacements have not been reported. Instead, it seems more likely that tiny particles could be detected by forces at contact because mechanoreceptors in the periodontal ligament that can detect these have been located (Trulsson \& Essick 2010). In fact, periodontal receptors regularly respond, not to the scale of forces of mastication in general (Trulsson 2006), but to the range of sub-Newton forces (Trulsson \& Johansson 1994, Trulsson \& Essick 2010) that we have shown would be required to detect those particles that could cause wear (Lucas et al. 2013). An additional mechanism by which wear could be avoided is by the sound that brittle fractures produce in the (human) mouth. A 'crunch' on a single dust particle, which is surprisingly loud, could convince a mammal that a source of potential wear has now definitely converted to a real danger. The sensing of very low forces via the periodontal ligament could confirm it.

On the anatomical level, enamels do vary in hardness (Lee et al. 2010, Constantino et al. 2011). In terms of dental anatomy, it seems possible to predict that harder exterior enamel should be favoured in mammals living in grittydusty environments. The need to fend off phytoliths as potential abrasives puts selective pressure on enamel to remain harder. Herbivores may face such a pressure. Of great interest in this regard are preliminary data indicating that the outer enamel of bovine incisors is approximately $12.4 \%$ harder than that of mice (D. A. Reed \& T. G. H. Diekwisch pers. comm.). The higher hardness of the bovine outer enamel also appears to be associated with a decrease in the ratio of $a: b$ diameters of the enamel crystallite. Increased sampling is needed to establish if this structuralfunctional relationship is representative of other ruminants and herbivores. However, these data do support the hypothesis that the feeding behaviour and dietary niche of ruminants necessitates unique design criteria within the enamel for resisting wear. 


\section{What role do phytoliths play in evading vertebrate feeding on plants?}

Suppose that plants deceive herbivorous vertebrates into thinking that their tissues are gritty by producing phytoliths. The first prediction from this is that phytoliths should be sub-millimetre, but multi-micron, sized particles (roughly isodiametric rather than sheet or plate-like) positioned close to the exterior of a plant. They could then be detected as though they were on the plant surface rather than deep to it. Perhaps more critical to this idea is that if plants grow in a perennially gritty environment, then selection for phytolith production should decrease. Lastly, it is not actually a requirement from a plant's point of view that a phytolith actually wears enamel, only that it appears to do so. Support for this is that the phytoliths studied here fracture in the same size range as grit particles, making them effective mimics.

Phytoliths have been produced by plants at least as far back as the Devonian (Carter 1999), making this physical deterrent about as ancient as the earliest chemical defences (Bak et al. 2006, Zagrobelny et al. 2008). The context in which we suggest phytoliths function as a grit-mimic is restricted to herbivorous vertebrates, largely mammals, whose upper and lower teeth can come into contact. Of course, these were not present in the Devonian. Yet we assume that, just as the form of any skeletal element can be modified to suit a plant's needs, phytoliths can be adapted likewise, both in physical form and mechanical properties (which are variable; Lucas et al. 2013). If the aim is to deter an invertebrate from walking across a surface, then sharp elongate phytoliths, as found in trichomes, thorns and spikes, will do this (Lucas et al. 2000). For an invertebrate like a locust, they act instead as cell-sized boulders that impede cell mechanical breakdown in the mouth, where it is important that they are angled to prevent them rolling out of contact (Hunt et al. 2008). However, for mammalian herbivores, we propose here that it is important that phytoliths fracture just like grit. The same morphology and particle dimensions apply as for a locust, but their material properties need to be fine-tuned to fracture at the same length scale. Sensitivity at this scale is probably vital because it is known that humans can detect particles of cellulose in the mouth, such as might be fractured from cell walls, as 'gritty', but only at sizes at least one order of magnitude larger (Imai et al. 1997). The same argument applies at yet larger scale to stone cells found within the flesh of some fruits that can also impart a 'gritty' texture (Smith 1935). Obviously, a herbivore needs to distinguish between pieces of cell wall (not injurious to enamel) and much smaller silica(te) particles from soils that can seriously damage it. It appears that the mouth is a small world after all.

Acceptance of the hypothesis presented here may involve some re-evaluation of existing observations. Biting invertebrates seem deterred by phytoliths (Massey et al. 2007), but it is unlikely that this is due to fear of wear because insect mandibles are soft enough to be worn heavily by plant cell walls anyway (Raupp 1985, Lucas et al. 1991, Schofield et al. 2011). The interference that phytoliths present to cellular fracture in the mouth seems a much more likely explanation of their deterrent effect (Hunt et al. 2008). Evidence is lacking that phloem-sucking insects, which pass their proboscises between cells and thus avoid phytoliths, are deterred by these structures (Massey et al. 2007). These sucking invertebrates are diverse and common in grassland habitats. So we hesitate to state firmly whether large vertebrates are now, or have always been, the dominant consumers of phytolith-laden grasses and therefore an important selective pressure on phytolith form. We do not know. Observations have often been biased towards their study (Morell 2007), although recent work in well-studied sites like the Serengeti (Dobson 2009) re-emphasizes their importance.

\section{Conclusions}

To cause wear to teeth, particulates must have a hardness greater than that of dental enamel and possess the correct angle of attack to induce fracture and the removal of this tooth tissue. Therefore, it seems that the main agents of wear are the dust and grit particles that adhere to foodstuffs. We have presented evidence demonstrating that dust and grit ingested on plant material can easily be fractured during mastication. This fracture 
would create the relevant angles of attack needed for tooth wear from "weathered" particulates and it would appear that these fracture events can be perceived by mammals via mechanoreceptors in the jaw. The perception and avoidance of these tiny fracture forces can be utilised by mammals to help limit the effects of tooth wear. Phytoliths, it seems, are not of a sufficient hardness to generate tooth wear. With this in mind, we propose the hypothesis that phytoliths, whilst not being the actual agents of wear, are instead deployed to mimic dust and grit during the mastication of plant tissue by animals, causing them to reduce or avoid consumption and therefore providing wear protection by deception.

\section{Acknowledgements}

We acknowledge support from Kuwait University General Facilities Project GE01/07 and GD02/11 for access to nanoindentation and a grant from the National Science Foundation HOMINID program (NSF BCS 0725126). We are grateful to John Damuth for very helpful comments that much improved the manuscript.

\section{References}

Anstis, G. R., Chantikal, P., Marshall, D. B. \& Lawn, B. R. 1981: Evaluation of indentation techniques for measuring fracture toughness: I. Direct crack measurements. Journal of the American Ceramic Society 64: 533-538.

Atkins, A. G. 2009a: Toughness and processes of material removal. - Wear 267: 1764-1771

Atkins, A. G. 2009b: The science and engineering of cutting. - Elsevier Press, Oxford.

Atkins, A. G. \& Mai, Y.-W. 1985: Elastic and plastic fracture. - Ellis Horwood, Chichester.

Atkins, A. G. \& Liu, J. H. 2007: Toughness and the transition between cutting and rubbing in abrasive contacts. Wear 262: 146-159.

Bajaj, D. \& Arola, D. 2009: On the R-Curve behavior of human tooth enamel. - Biomaterials 30: 4037-4046.

Bak, S., Paquette, S. M., Morant, M., Vinther Morant, A., Saito, S., Bjarnholt, N., Zagrobelny, M., Jørgensen, K., Osmani, S., Simonsen, H. T., Sanchez-Pérez, R., van Heeswijck, T. B., Jørgensen, B. \& Lindberg-Møller, B. 2006: Cyanogenic glycosides: a case study for evolution and application of cytochromes P450. - Phytochemistry Reviews 5: 309-329.

Barani, A., Keown, A. J., Bush, M. B., Lee, J. J.-W. \& Lawn, B. R. 2012: Role of tooth elongation in promoting fracture resistance. - Journal of the Mechanical Behavior of Biomedical Materials 8: 37-46.
Broz, M. B., Cook, R. F. \& Whitney, D. L. 2006: Microhardness, toughness, and modulus of Mohs scale minerals. - American Mineralogist 91: 135-142.

Carter, J. A. 1999: Late Devonian, Permian and Triassic phytoliths from Antarctica. - Micropaleontology 45: 56-61.

Chai, H., Lee, J. J.-W. \& Lawn, B. R. 2011: On the chipping and splitting of teeth. - Journal of the Mechanical Behavior of Biomedical Materials 4: 315-321.

Constantino, P., Lee, J. J.-W., Chai, H., Zipfel, B., Ziscovici, C., Lawn, B. R. \& Lucas, P. W. 2010: Tooth chipping can reveal the diet and bite forces of fossil hominins. Biology Letters 6: 719-722.

Constantino, P. J., Lee, J. J.-W., Morris, D., Lucas, P. W., Hartstone-Rose, A., Lee, W.-K., Dominy, N. J., Cunningham, A., Wagner, M. \& Lawn, B. R. 2011: Adaptation to hard object eating in sea otters and hominins. - Journal of Human Evolution 61: 89-96.

Cuy, J. L., Mann, A. B., Livi, K. J., Teaford, M. F. \& Weihs, T. P. 2002: Nanoindentation mapping of the mechanical properties of human molar tooth enamel. - Archives of Oral Biology 7: 281-291.

Cuozzo, F. P. \& Sauther, M. L. 2006: Severe wear and tooth loss in wild ring-tailed lemurs (Lemur catta): a function of feeding ecology, dental structure, and individual life history. - Journal of Human Evolution 51: 490-505.

Damuth, J. \& Janis, C. M. 2011: On the relationship between hypsodonty and feeding ecology in ungulate animals, and its utility in palaeoecology. - Biological Reviews 86: 733-758.

Daphalapurkar, N. P., Wang, F., Fu, B., Lu, H. \& Komanduri, R. 2011: Determination of mechanical properties of sand grains by nanoindentation. - Experimental Mechanics 51: 719-728.

Darvell, B. W. 1990: On uniaxial compression tests and the validity of indirect tensile strength. - Journal of Materials Science 15: 757-780.

Dobson, A. 2009: Food-web structure and ecosystem services: insights from the Serengeti. - Philosophical Transactions of the Royal Society London B 364: 1665-1682.

Engelbrecht, J. P., McDonald, E. V., Gillies, J. A. \& Gertler, A. W. 2008: Department of Defense Enhanced Particulate Matter Surveillance Program Final Report. Desert Research Institute, Reno, NV.

Engelen, L., van der Bilt, A., Schipper, M. \& Bosman, F. 2005: Oral size perception of particles: effect of size, type, viscosity and method. - Journal of Texture Studies 36: 373-386.

Fortelius, M. 1985: Ungulate cheek teeth: developmental, functional, and evolutionary interrelations. - Acta Zoologica Fennica 180: 1-76.

Fortelius, M. \& Solounias, N. 2000: Functional characterization of ungulate molars using the abrasion-attrition wear gradient: a new method for reconstructing paleodiets. American Museum Novitates 3301: 1-36.

Guidoni, G. M., Swain, M. V. \& Jäger, I. 2009: Wear behaviour of dental enamel at the nanoscale with a sharp and blunt indenter tip. - Wear 266: 60-68.

Hiramatsu, Y. \& Oka, Y. 1966: Determination of the tensile strength of rock by a compression test of an irregular test 
piece. - International Journal of Rock Mechanics and Mining Sciences and Geomechanics 3: 89-90.

Hummel, J., Findeisen, E., Südekum, K.-H., Ruf, I., Kaiser, T. M. \& Bucher, M. 2011: Another one bites the dust: faecal silica levels in large herbivores correlate with high-crowned teeth. - Proceedings of the Royal Society London B 278: 1742-1747.

Hunt, J. W., Dean, A. P., Webster, R. E., Johnson, G. N. \& Ennos, A. R. 2008: A novel mechanism by which silica defends grasses against herbivory. - Annals of Botany 102: 653-656.

Imai, E., Hatae, K. \& Shimada, A. 1995: Oral perception of grittiness: effect of particle size and concentration of the dispersed particles and their dispersion medium. Journal of Texture Studies 26: 561-576.

Imai, E., Shimichi, Y., Maruyama, I., Inoue, A., Ogawa, S. \& Hatae, K. \& Shimada, A. 1997: Perception of grittiness in an oil-in-water emulsion. - Journal of Texture Studies 28: 257-272.

Janis, C. M. \& Fortelius, M. 1988: On the means whereby mammals achieve increased functional durability of their dentitions, with special reference to limiting factors. Biological Reviews 63: 197-230.

Jones, L. H. P. \& Milne, A. A. 1966: Studies of silica in the oat plant I. Chemical and physical properties of the silica. - Plant Soil 18: 207-220.

Kadohisa, M., Verhagen, J. V. \& Rolls, E. T. 2005: The primate amygdala: neuronal representations of the viscosity, fat texture, temperature, grittiness and taste of foods. - Neuroscience 132: 33-48.

Kaiser, T. M., Müller, D. W. H., Fortelius, M., Schulz, E., Codron, D. \& Clauss, M. 2013: Hypsodonty and tooth facet development in relation to diet and habitat in herbivorous ungulates: implications for understanding tooth wear. - Mammal Review 43: 34-46.

Kendall, K. 1978a: Complexities of compression failure. - Proceedings of the Royal Society London A 361: 245-263.

Kendall, K. 1978b: The impossibility of comminuting small particles by compression. - Nature 272: 710-711.

King, S. J, Arrigo-Nelson, S. J., Pochron, S. T., Semprebon, G. M., Godfrey, L. R., Wright, P. C. \& Jernvall, J. 2005: Dental senescence in a long-lived primate links infant survival to rainfall. - Proceedings of the National Academy of Sciences USA 102:16579-16583.

Lanyon, J. M. \& Sanson, G. D. 1986: Koala (Phascolarctos cinereus) dentition and nutrition. II. Implications of tooth wear in nutrition. - Journal of Zoology (London) 209: 169.

Lawn, B. R., Bush, M. B. Barani, A. \& Constantino, P. J. 2013: Inferring biological evolution from fracture patterns in teeth. - Journal of Theoretical Biology 338: $59-65$.

Lee, J. J.-W., Morris, D., Constantino, P., Chai, H., Lucas, P. W., Smith, T. M. \& Lawn, B. R. 2010: Properties of tooth enamel in Great Apes. - Acta Biomaterialia 12: 4560-4565.

Lee, J. J.-W., Constantino, P., Lucas, P. W. \& Lawn, B. R. 2011: Fracture in teeth - a diagnostic for inferring tooth function and diet. - Biological Reviews 86: 959-974.
Lucas, P. W. 2004: Dental functional morphology. - Cambridge University Press, Cambridge.

Lucas, P. W., Turner, I. M., Dominy, N. J. \& Yamashita, N. 2000: Mechanical defences to herbivory. - Annals of Botany 86: 913-920.

Lucas, P. W., Constantino, P., Wood, B. A. \& Lawn, B. R. 2008: Dental enamel as a dietary indicator in mammals. - Bioessays 30: 374-285.

Lucas, P. W., Lowrey, T. K., Pereira, B., Sarafis, V. \& Kuhn, W. 1991: The ecology of Mezzettia leptopoda Hk. f. et Thoms. (Annonaceae) seeds as viewed from a mechanical perspective. - Functional Ecology 5: 345-353.

Lucas, P. W., Omar, R., Al-Fadhalah, K., Almusallam, A. S., Henry, A. G., Michael, S., Arockia Thai, L., Watzke, J., Strait, D. S. \& Atkins, A. G. 2013: Mechanisms and causes of wear in tooth enamel: implications for hominin diets. - Interface, Journal of The Royal Society 10: 20120923, doi: 10.1098/rsif.2012.0923.

Lutgens, F. K. \& Tarbuck, E. J. 2000: Essentials of geology, 7th ed. - Prentice Hall, Englewood Cliffs, NJ.

Massey, F. P., Ennos, R. \& Hartley, S. E. 2007: Herbivore specific induction of silica-based plant defences. Oecologia 152: 677-683.

Massey, F. P., Massey K., Ennos, R. \& Hartley, S. E. 2009: Impacts of silica-based defences in grasses on the feeding preferences of sheep. - Basic Applied Ecology 10: 622-630.

McDowell, G. R. \& Bolton, M. D. 1998: On the micromechanics of crushable aggregates. - Géotechnique 48: 667-679.

Morell, V. 2007: Counting creatures of the Serengeti, great and small. - Science 278: 2058.

Oliver, W. C. \& Pharr, G. M. 1992: An improved technique for determining hardness and elastic modulus using load and displacement sensing indentation experiments. Journal of Materials Research 7: 1564-1583.

Pharr, G. M. 1998: Measurement of mechanical properties by ultra-low load indentation. - Materials Science and Engineering A 253: 151-159.

Piperno, D. R. 2006: Phytoliths: a comprehensive guide for archaeologists and paleoecologists. - Altamira Press, Lanham, MD.

Puttick, K. E. Shahid, M. A. \& Hosseini, M. M. 1979: Size effects in abrasion of brittle materials. - Journal of Physics D 12: 195-202.

R Core Team 2013: $R$ : a language and environment for statistical computing. - $\mathrm{R}$ Foundation for Statistical Computing, Vienna, Austria. [Available at http:// www.R-project.org].

Raupp, M. J. 1985: Effects of leaf toughness on mandibular wear in the leaf beetle, Plagiodera versicolora. - Ecological Entomology 10: 73-79.

Riede, F. \& Wheeler, J. M. 2009: Testing the 'Laacher See hypothesis': tephra as dental abrasive. - Journal of Archaeological Science 39: 2384-2391.

Schofield, R. M. S., Emmett, K. D., Niedbala, J. C. \& Nesson, M. H. 2011: Leaf-cutter ants with worn mandibles cut half as fast, spend twice the energy, and tend to carry instead of cut. - Behavioral Ecology and Sociobiology 65: 969-982. 
Shipway, P. H. \& Hutchings, I. M. 1993a: Fracture of brittle spheres under compression and impact loading. 1. Elastic stress distributions. - Philosophical Magazine A 67: 1389-1404.

Shipway, P. H. \& Hutchings, I. M. 1993b: Attrition of brittle spheres by fracture under compression and impact loading. - Powder Technology 76: 23-30.

Shipway, P. H. \& Hutchings, I. M. 1996: The role of particle properties in the erosion of brittle materials. - Wear 193: 105-113.

Smith, W. W. 1935. The course of stone cell formation in pear fruits. - Plant Physiology 10: 587-611.

Strömberg, C. A. E., Dunn, R. E., Madden R. H., Kohn, M. J. \& Carlini, A. A. 2013: Decoupling the spread of grasslands from the evolution of grazer-type herbivores in South America. - Nature Communications 4, 1478, doi: $10.1038 /$ ncomms 2508
Trulsson, M. 2006: Sensory-motor function of human periodontal mechanoreceptors. - Journal of Oral Rehabilitation 33: 262-273

Trulsson, M. \& Johansson, R. S. 1994: Encoding of amplitude and rate of forces applied to the teeth by human periodontal mechanoreceptive afferents. - Journal of Neurophysiology 72: 1734-1744.

Trulsson, M. \& Essick, G. K. 2010: Sensations evoked by microstimulation of single mechanoreceptive afferents innervating the human face and mouth. - Journal of Neurophysiology 103: 1741-1747.

Whitney, D. L., Broz, M. \& Cook, R. F. 2007: Hardness, toughness and modulus of some common metamorphic minerals. - American Mineralogist 92: 281-288.

Zagrobelny, M., Bak, S. \& Møller, B. L. 2008: Cyanogenesis in plants and arthropods. - Phytochemistry 69: $1457-1468$. 